\title{
Primary pyogenic spondylitis following kyphoplasty: a case report
}

\author{
Markus D Schofer", Stefan Lakemeier, Christian D Peterlein, Thomas J Heyse, Markus Quante
}

\begin{abstract}
Introduction: Only ten cases of primary pyogenic spondylitis following vertebroplasty have been reported in the literature. To the best of our knowledge, we present the first reported case of primary pyogenic spondylitis and spondylodiscitis caused by kyphoplasty.

Case presentation: A 72-year old Caucasian man with an osteoporotic compression fracture of the first lumbar vertebra after kyphoplasty developed sensory incomplete paraplegia below the first lumbar vertebra. This was caused by myelon compression following pyogenic spondylitis with a psoas abscess. Computed tomography guided aspiration of the abscess cavity yielded group C Streptococcus. The psoas abscess was percutaneously drained and laminectomy and posterior instrumentation with an internal fixator from the eleventh thoracic vertebra to the fourth lumbar vertebra was performed. In a second operation, corpectomy of the first lumbar vertebra with cement removal and fusion from the twelfth thoracic vertebra to the second lumbar vertebra with a titanium cage was performed. Six weeks postoperatively, the patient was pain free with no neurologic deficits or signs of infection.
\end{abstract}

Conclusion: Pyogenic spondylitis is an extremely rare complication after kyphoplasty. When these patients develop recurrent back pain postoperatively, the diagnosis of pyogenic spondylitis must be considered.

\section{Introduction}

Vertebroplasty and kyphoplasty are discussed critically in the literature [1-6]. The overall risks of these procedures are low and more severe complications such as spinal cord compression or pulmonary embolism are very rare (0.01\%-0.03\%) after kyphoplasty [2]. Older patients undergoing kyphoplasty may have risk factors for immunocompromise, such as diabetes or renal insufficiency. Until now, there have been no reported cases of primary pyogenic spondylitis or spondylodiscitis after kyphoplasty.

\section{Case presentation}

A 72-year-old Caucasian man, with a past medical history of mild Parkinson's disease, hypertension, coronary artery disease and cardiac insufficiency, complained of four weeks of back pain. Physical examination and imaging with computed tomography (CT) and magnetic resonance imaging (MRI) revealed a recent osteoporotic

\footnotetext{
* Correspondence: schofer@med.uni-marburg.de
Department of Orthopaedics, University Hospital Marburg, Baldingerstrasse,

* Correspondence: schofer@med.uni-marburg.de 35033 Marburg, Germany
}

(c) 2011 Schofer et al; licensee BioMed Central Ltd. This is an Open Access article distributed under the terms of the Creative Commons Attribution License (http://creativecommons.org/licenses/by/2.0), which permits unrestricted use, distribution, and reproduction in any medium, provided the original work is properly cited. fracture of the L2 endplate. The patient underwent the initial operation at an outside institution; bilateral transpedicular L1 kyphoplasty was performed, using the Kyphon ${ }^{\circledR}$ (Sunnyvale, CA, USA) kyphoplasty system with polymethylmethacrylate cement. A single dose of antibiotic prophylaxis (cefazolin sodium USP, $2 \mathrm{~g}$ ) was administered preoperatively. Intraoperatively, a bone cylinder biopsy was taken; histological examination showed no evidence of malignancy or infection. Plain radiographs demonstrated satisfactory placement of the cement in the vertebral body (Figure 1). He was discharged on the postoperative day six pain free and neurologically intact.

Six weeks after the initial operation, the patient complained of worsening thoracolumbar back pain (Visual Analogue Scale (VAS) 8) requiring hospitalization. On physical examination, incomplete sensory paraplegia below the L1 dermatome was present without motor impairment. The white blood cell count was $14,800 \mathrm{G} / \mathrm{L}$ (normal range 4000-10,000 G/L) and the C-reactive protein level was $75 \mathrm{mg} / \mathrm{L}$ (normal range $0-5 \mathrm{mg} / \mathrm{L}$ ). Plain 


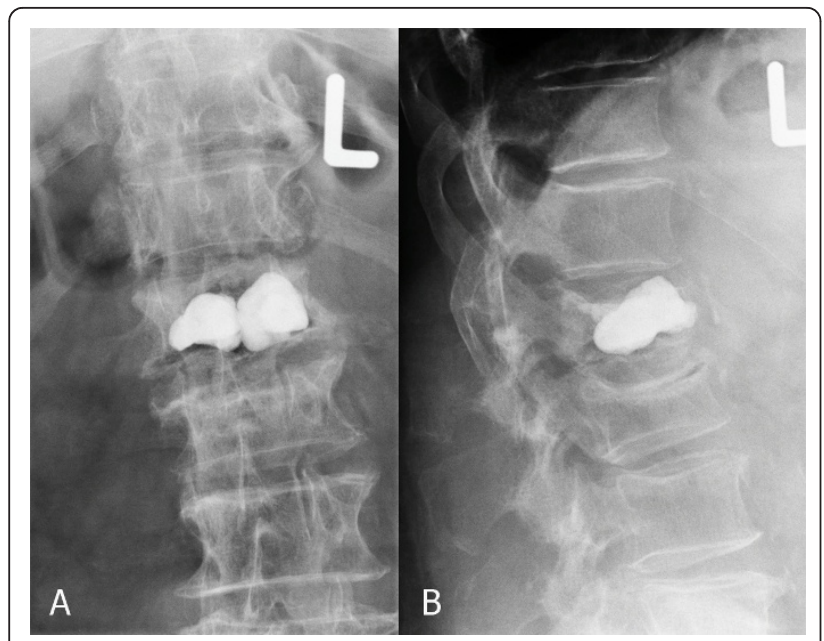

Figure 1 Plain (A) and lateral (B) thoracolumbar radiographs (T11 - L3) taken after initial kyphoplasty for treatment of an L1 compression fracture. The cement is correctly positioned in the vertebral body.

radiographs demonstrated destruction and subtotal resorption of the L1 vertebra, with the cement filling displaced and exposed (Figure 2). In addition, MRI revealed L1 spondylitis with a right-sided psoas abscess and compression of the lumbar spinal cord (Figure 3).

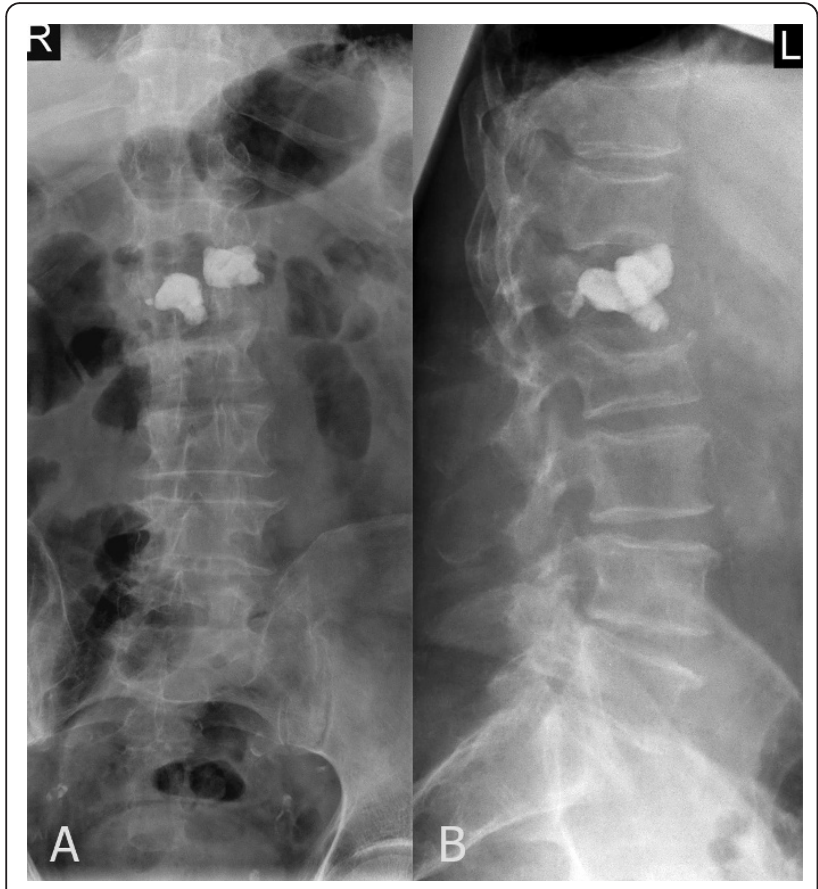

Figure 2 Anterior posterior (A) and lateral (B) thoracolumbar radiographs (T11 - S1) six weeks after initial kyphoplasty. The L1 vertebral body is partially resorbed. The osseous structure of the L1 vertebral body cannot be delineated. The position of the left cement block has shifted anteriorly and rostrally.

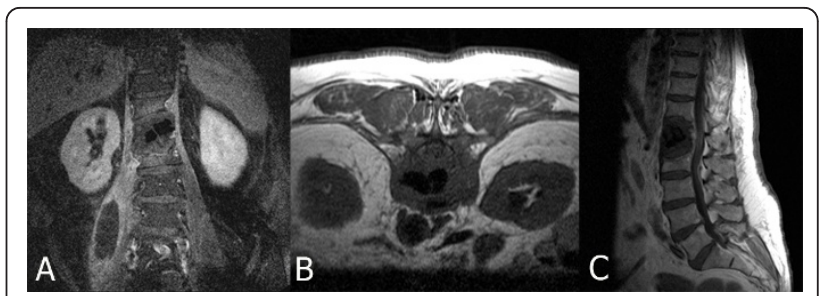

Figure 3 The magnetic resonance imaging T1 gadoliniumenhanced coronal image (A) shows spondylitis and a rightsided psoas abscess. $\mathrm{T} 1$ without contrast transverse image of $\mathrm{L} 1$ (B) demonstrates the compressed spinal canal and inflamed right psoas muscle. T1 sagittal image (C) shows spinal cord compression.

These findings were consistent with a diagnosis of pyogenic spondylitis of the L1 vertebra after kyphoplasty.

Re-exploration was recommended but was refused by the patient due to his poor general medical condition, although he was informed about the risk of a progression to complete paralysis. The patient underwent CTguided aspiration and drainage of the psoas abscess. Cultures grew group C hemolytic Streptococcus. He was initially treated conservatively with a six-week course of cefuroxime and clindamycin. The abscess cavity was irrigated daily with normal saline until drain removal on post procedure day six.

The patient's symptoms progressed to leg paresis without neurogenic bladder and/or bowel dysfunction. He gave informed consent and underwent re-exploration with dorsal spinal decompression, T12/L1 laminectomy and T11 - L4 fusion using transpedicular fixation with a dural rod system $\left(\mathrm{Xia}^{\mathbb{B}}\right.$, Stryker Howmedica ${ }^{\mathbb{B}}$, Keil, Germany). In a second procedure on postoperative day 10 , ventral transphrenic bisegmental spondylodesis was performed. After the removal of the residual L1 vertebra with the cement body, adjacent discs and osteolytic endplates, an intracorporal stand-alone titanium cage (Obelisc, Ulrich Medical, Ulm, Germany) was implanted between T12 and L2. The patient was transferred to the inpatient rehabilitation unit after 11 days. He made an uneventful recovery and his back pain improved significantly (VAS 3). His neurological symptoms regressed after six weeks, with normal biochemistry and no signs of ongoing inflammation. At discharge, his pain was a VAS 2; six months later, he was symptom free and completely ambulatory without assistance (Figure 4). After 24 months, he had no complaints, neurologic deficit or signs of infection. Plain radiographs demonstrated no pseudarthrosis or dislocation of screws, rods or the cage (Figure 4).

\section{Discussion}

This is the first reported case of an infectious complication after kyphoplasty. Since 1998, kyphoplasty has been 


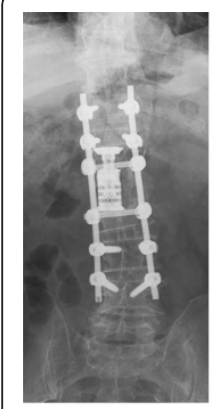

6 month

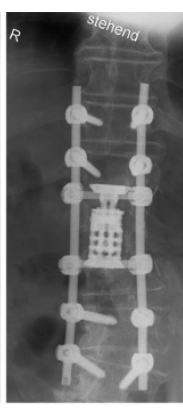

24 month

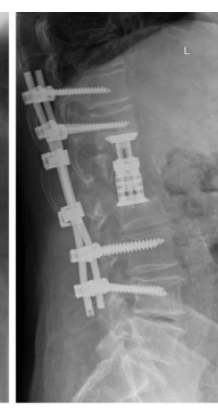

6 month
Time after surgery

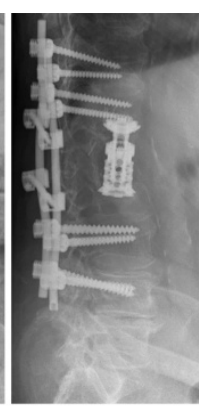

24 month

Figure 4 Anterior posterior (AP) and lateral plain thoracolumbar radiographs six and $\mathbf{2 4}$ months after reconstruction and spondylodesis (T11 - L4). We performed the transpedicular fixation with a dual rod system and vertebral replacement of the L1 vertebra using an expandable cage. Reconstruction is stable on both AP and lateral views at six months. Follow-up radiographs at 24 months show no signs of pseudarthrosis or infection.

gaining popularity for the treatment of symptomatic compression fractures as outcomes have been shown to be good $[2,4]$. Apart from asymptomatic cement leakage, the morbidity is low. Complications after vertebroplasty are also minimal, although there are 10 published cases of primary pyogenic spondylitis after vertebroplasty (Table 1) [7-15]. Only one of these cases was without a significant past medical history. Three were on immunosuppressive medications, three had diabetes mellitus, three were diagnosed with acute urinary tract infections prior to vertebroplasty and one patient had Child's A cirrhosis of the liver secondary to prolonged alcohol abuse [8,11-13]. In addition, one patient had a grade II decubitus ulcer [12]. In four, treatment was conservative without surgical intervention [9-12]. The remaining six patients underwent reexploration to remove residual material and achieve further stabilization [7,12-15]. One patient with pyogenic spondylitis of T12 following T11 vertebroplasty was treated with drainage at T12 and subsequent vertebroplasty using antibiotic cement [8].

There is no established evidence as to why more infectious complications have been observed in vertebroplasty versus kyphoplasty. However, the incidence of infectious complications may be attributable to comorbidities, suggesting that high-risk patients may need specific prophylactic antibiotic treatment in order to avoid pyogenic spondylitis. Before our patient's initial kyphoplasty, preoperative imaging and blood tests did not indicate an infectious source in the vertebral body; the bone cylinder biopsy did not show signs of malignancy or infection. Therefore, it is unlikely that an infection that caused the spondylitis was already present. Although the patient had a history of Parkinson's disease and coronary artery disease, these are not regarded as contraindications to kyphoplasty. However, postoperative morbidity may be increased with these comorbidities. One possible cause

Table 1 Literature review of 10 reported cases of pyogenic spondylitis following vertebroplasty

\begin{tabular}{|c|c|c|c|c|c|c|}
\hline Author & $\begin{array}{l}\text { Affected } \\
\text { vertebral } \\
\text { body }\end{array}$ & Side diagnosis & Age & Bacterium & Therapy & $\begin{array}{l}\text { Time from } \\
\text { vertebroplasty } \\
\text { until infection }\end{array}$ \\
\hline $\begin{array}{l}\text { Deramond } \\
\text { [9] }\end{array}$ & Unstated & Immunosuppressive therapy & Unstated & No detection & Conservative & Unstated \\
\hline $\begin{array}{l}\text { Kallmes } \\
{[10]}\end{array}$ & $\mathrm{T} 12$ & Immunosuppressive therapy & Unstated & Staphylococcus epidermidis & Conservative & 1 month \\
\hline Yu [14] & $\mathrm{T} 12$ & Urinary tract infection & 78 & No detection & $\begin{array}{l}\text { Dorsoventral } \\
\text { stabilization }\end{array}$ & 1 month \\
\hline Walker [13] & $\mathrm{T} 11$ and $\mathrm{T} 12$ & $\begin{array}{l}\text { Urinary tract infection, } \\
\text { cholecystitis, meningitis, } \\
\text { diabetes mellitus }\end{array}$ & 64 & Enterobacter species & $\begin{array}{l}\text { Dorsoventral } \\
\text { stabilization }\end{array}$ & 11 days \\
\hline Walker [13] & L3 & $\begin{array}{l}\text { Discectomy after } \\
\text { spondylodiscitis T12/L1 }\end{array}$ & 49 & Staphylococcus aureus & $\begin{array}{l}\text { Dorsoventral } \\
\text { stabilization }\end{array}$ & 8 months \\
\hline $\begin{array}{l}\text { Schmid } \\
{[11]}\end{array}$ & $L 3-L 5$ & Liver cirrhosis, alcohol abuse & 55 & No detection & Conservative & 2 weeks \\
\hline Alfonso [7] & L3 & None & 63 & $\begin{array}{l}\text { Serratia marcescens, } \\
\text { Stenotrophmonas maltophilia, } \\
\text { Burkholderia cepacia }\end{array}$ & $\begin{array}{l}\text { Dorsoventral } \\
\text { stabilization }\end{array}$ & 1 month \\
\hline Vats [12] & L1 & $\begin{array}{l}\text { Diabetes mellitus, decubital } \\
\text { ulcus II }\end{array}$ & 73 & Streptococcus agalactiae & Conservative & 6 months \\
\hline $\operatorname{Lin}[15]$ & $\mathrm{T} 12$ & $\begin{array}{l}\text { Immunosuppressive therapy, } \\
\text { urinary tract infection }\end{array}$ & 65 & Acinetobacter species & Ventral stabilization & 6 months \\
\hline Chen [8] & $\mathrm{T} 11$ & $\begin{array}{l}\text { Diabetes mellitus, } \\
\text { vertebroplasty T12 }\end{array}$ & 95 & Proprioni acnes & $\begin{array}{l}\text { Drainage with } \\
\text { subsequent } \\
\text { vertebroplasty }\end{array}$ & 2 months \\
\hline
\end{tabular}


for an iatrogenic pyogenic infection could be contamination from skin flora [16]. Pyogenic spondylitis and spondylodiscitis following spinal anesthesia have been reported and this may have been the case in our patient; if so, a single dose antibiotic prophylaxis with a firstgeneration cephalosporin may have been inadequate. To date, there are no official guidelines for antibiotic prophylaxis in spinal surgery.

The cement traditionally used in kyphoplasty does not contain antibiotics. However, the increasing use of antibiotic cement in endoprosthetic surgery is documented. The use of antibiotic cement must be evaluated bearing in mind a patient's individual risk factors, such as age and comorbidities. In immunocompromised patients, the use of antibiotic cement and prolonged perioperative antibiotic prophylaxis should be considered in order to avoid infectious complications. In our case, we propose that there may be a benefit from the use of antibiotic cement in spine augmentation. This area requires further investigation with controlled studies.

In addition, early and emergent spinal cord decompression of the spinal cord is the standard of care. Conservative treatment in this situation is not ideal but we were limited by the patient's refusal to proceed with our initial recommendations. In this case, the primary presenting symptom was recurrent severe back pain. Therefore, severe back pain after a pain-free interval following kyphoplasty must be investigated in order to rule out pyogenic spondylitis. Another diagnosis in the differential that should be considered in such a scenario, especially without adjacent segment fractures, is vertebral necrosis associated with cement injection.

\section{Conclusion}

Complications following kyphoplasty are rare, especially compared with the number of surgeries performed. In pyogenic spondylitis, treatment is laborious and extends over a long period, often involving multiple surgeries. In elderly patients and those with multiple comorbidities, pyogenic spondylitis can be life-threatening. Therefore, antibiotic prophylaxis is likely to be extremely important for the prevention of infectious complications following kyphoplasty in high-risk patients. In these patients, antibiotic cement should be considered.

\section{Consent}

Written informed consent was obtained from the patient for publication of this case report and any accompanying images. A copy of the written consent is available for review by the Editor-in-Chief of this journal. fourth lumbar vertebra; CT: computed tomography; MRI: magnetic resonance imaging; VAS: visual analog scale.

\section{Authors' contributions}

MDS, SL, CDP, TJH and MQ analyzed and interpreted the patient data. MDS performed the surgery. MDS and MQ were the main authors of the manuscript. All authors read and approved the final manuscript.

\section{Competing interests}

The authors declare that they have no competing interests.

Received: 14 March 2010 Accepted: 13 March 2011

Published: 13 March 2011

\section{References}

1. Garfin SR, Buckley RA, Ledlie J: Balloon kyphoplasty for symptomatic vertebral body compression fractures results in rapid, significant, and sustained improvements in back pain, function and quality of life for elderly patients. Spine 2006, 31:2213-2220.

2. Hulme PA, Krebs J, Ferguson SJ, Berlemann U: Vertebroplasty and kyphoplasty: a systematic review of 69 clinical studies. Spine 2006, 31:1983-2001.

3. Ledlie JT, Renfro MB: Kyphoplasty treatment of vertebral fractures: 2-year outcomes show sustained benefits. Spine 2006, 31:57-64.

4. Schofer MD, Efe T, Timmesfeld N, Kortmann HR, Quante M: Comparison of kyphoplasty and vertebroplasty in the treatment of fresh vertebral compression fractures. Arch Orthop Trauma Surg 2009, 129:1391-1399.

5. Buchbinder $R$, Osborne RH, Ebeling PR, Wark JD, Mitchell P, Wriedt $C$, Graves S, Staples MP, Murphy B: A randomized trial of vertebroplasty for painful osteoporotic vertebral fractures. N Engl J Med 2009, 361:557-568.

6. Kallmes DF, Comstock BA, Heagerty PJ, Turner JA, Wilson DJ, Diamond TH, Edwards R, Gray LA, Stout L, Owen S, et al: A randomized trial of vertebroplasty for osteoporotic spinal fractures. N Engl J Med 2009, 361:569-579.

7. Alfonso Olmos M, Silva Gonzalez A, Duart Clemente J, Villas Tome C: Infected vertebroplasty due to uncommon bacteria solved surgically: a rare and threatening life complication of a common procedure: report of a case and a review of the literature. Spine 2006, 31:E770-773.

8. Chen LH, Yang SC, Niu CC, Lai PL, Chen WJ: Percutaneous drainage followed by antibiotic-impregnated cement vertebroplasty for pyogenic vertebral osteomyelitis: a case report. J Trauma 2008, 64:E8-11.

9. Deramond H, Depriester C, Galibert P, Le Gars D: Percutaneous vertebroplasty with polymethylmethacrylate. Technique, indications, and results. Radiol Clin North Am 1998, 36:533-546.

10. Kallmes DF, Jensen ME: Percutaneous vertebroplasty. Radiology 2003, 229:27-36.

11. Schmid KE, Boszczyk BM, Bierschneider M, Zarfl A, Robert B, Jaksche H: Spondylitis following vertebroplasty: a case report. Eur Spine J 2005, 14:895-899.

12. Vats HS, McKiernan FE: Infected vertebroplasty: case report and review of literature. Spine 2006, 31:E859-862.

13. Walker DH, Mummaneni P, Rodts GE Jr: Infected vertebroplasty. Report of two cases and review of the literature. Neurosurg Focus 2004, 17:E6.

14. Yu SW, Chen WJ, Lin WC, Chen YJ, Tu YK: Serious pyogenic spondylitis following vertebroplasty - a case report. Spine 2004, 29:E209-211.

15. Lin WC, Lee CH, Chen SH, Lui CC: Unusual presentation of infected vertebroplasty with delayed cement dislodgment in an immunocompromised patient: case report and review of literature. Cardiovasc Intervent Radiol 2008, 31(Suppl 2):S231-235.

16. Cogen AL, Nizet $V$, Gallo RL: Skin microbiota: a source of disease or defence? Br J Dermatol 2008, 158:442-455.

doi:10.1186/1752-1947-5-101

Cite this article as: Schofer et al:. Primary pyogenic spondylitis following kyphoplasty: a case report. Journal of Medical Case Reports 2011 5:101. 